\title{
THE EFFECTS OF TWO COMPUTERIZED PROGRAMS IN REDUCING JORDANIAN TERTIARY STUDENTS' SPELLING ERRORS
}

\section{ABSTRACT}

\author{
Dr. Khalid Mahmoud Al-zuoud \\ University of Hai'l
}

\begin{abstract}
This study investigated the effects of using two computerized programs on reducing the spelling errors Jordanian tertiary students. Ginger and Microsoft Word 2007 were used as two modes of presentation. These programs represented the text-audio and text modes, respectively, according to the modality principle. The spelling error levels (i.e., high, medium, and low) of the students were compared. This study was conducted based on Mayer's cognitive theory of multimedia learning, dual route theory of efficient spelling, and spelling in the context approach. The modality principle was similarly used as an effective tool for improving the spelling performance and reducing the spelling errors of students. The study sample comprised 80 male and female second-year students who were purposefully selected from Hashemite University in Jordan. Both study groups took pre- and post-tests as well as participated in structured interviews to answer the main questions of the study. The spelling errors of these Jordanian students were classified into four types according to Cook's classification. the interference between the Arabic and English languages was clarified. The phonological differences between these languages may cause many spelling mistakes that may also affect how students pronounce words. The modality principle must be integrated into the instructional, curriculum, computer-based, and web-based designs to help students develop their spelling performance. EFL professors are encouraged to use programs with contextual spelling features for teaching their students how to spell. Future studies must investigate the effects of these contextual features on other language skills, such as pronunciation, grammar, and vocabulary. These studies must also measure the effects of using computerized programs on how students pronounce words.
\end{abstract}

Keywords: Omission; Insertion; Substitution; Transposition; text-audio mode; text mode.

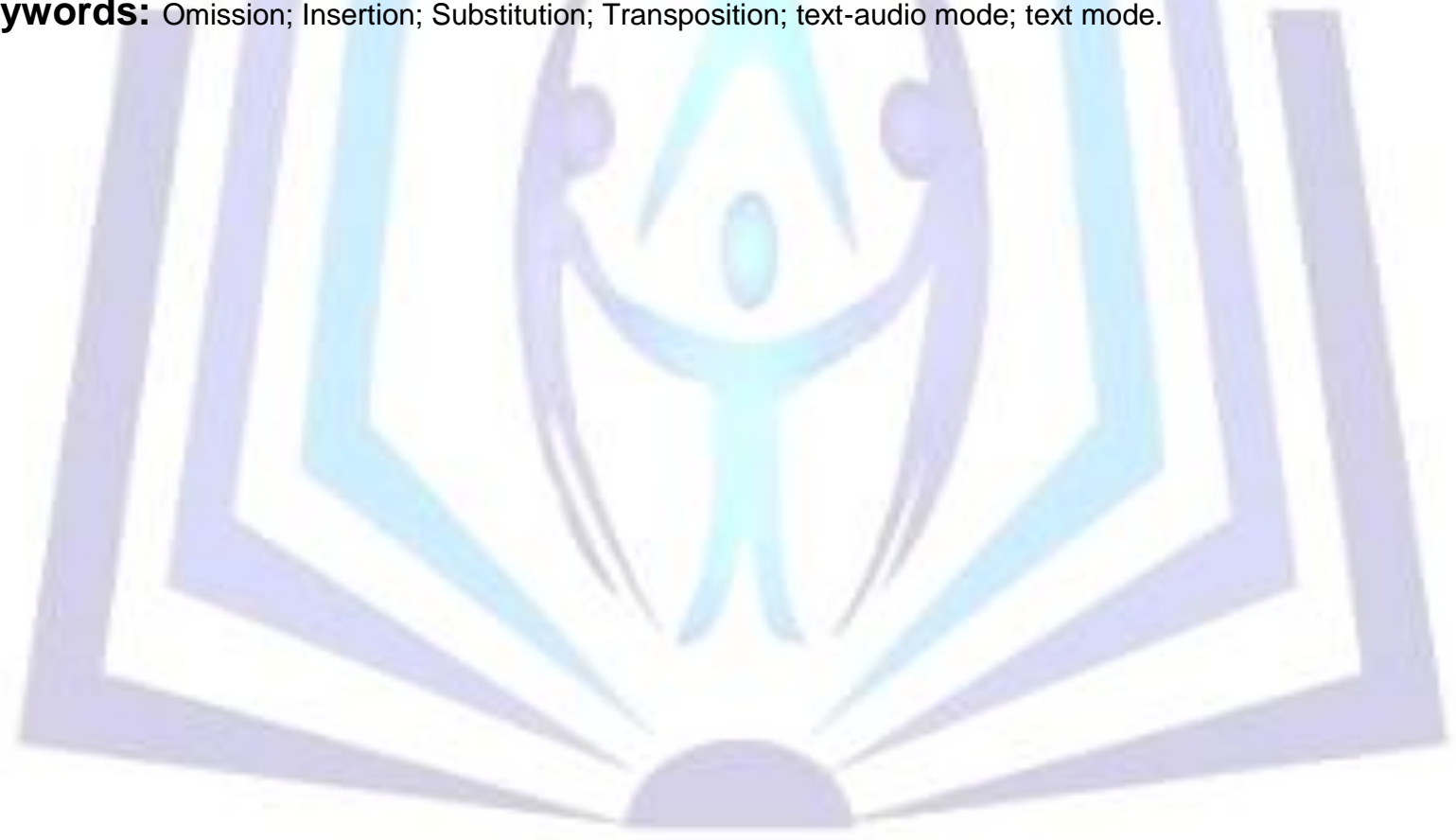

\section{Council for Innovative Research}

Peer Review Research Publishing System

Journal: Journal of Advances in Linguistics

Vol .5 No 2

editor@cirjal.com

www.cirjal.com, www.cirworld.com 


\section{BACKGROUND}

This study investigates the effects of technology on the English language, specifically on English spelling.

The world has witnessed the phenomenal growth in the usage of information and communication technology (ICT) in the field of education. Integrating ICT into language learning classes may create interaction among learners and affect the teaching process. Various means of technology, such as teleconferencing, online and web-based instruction, and elearning, are employed in the teaching and learning process in teaching writing; meanwhile, the Internet and web-based programs (Park \& Son, 2009) have been used and affected student essays in terms of organization, grammar, and mechanics. Research indicates that teaching writing through computers can reduce student errors (Chen \& Cheng, 2006). For instance, computer programs identify and correct the spelling errors of students in both words and the context, thus helping students to recognize and correct such errors. Computers can easily identify and codify these errors. Similarly, simple matching procedures can be used to flag errors and improve the writing quality of students (Eliot \& Mikulua, 2004). The writing quality of students is improved by providing them with accurate feedback, which encourages them to reduce writing errors and increase editing activity in their writing. Moreover, receiving good feedback on errors increases student awareness and reduces errors, thereby reflecting the quality of writing. Computers affect student writing in several aspects, such as general competence, organization, and writing mechanics.

Both students and teachers can benefit from ICT use in the context of teaching English as a foreign language (EFL) or English as a second language (ESL) (Albirini, 2004). ICT enhances the language skills (i.e., speaking, reading, grammar, coherence in writing, and syntax) of students; moreover, it contributes to learner awareness of the language (Kapka \& Oberman, 2001). ICT supports creativity and independent learning as well as provides various forms of presenting information. Meanwhile, ICT provides teachers with different types of media that can be used in conveying messages in a manner that differs from the traditional one. Moreover, ICT helps teachers to communicate their ideas and experiences with each other.

One of the most important areas in writing is spelling, and this study has selected spelling as its focus. Spelling is more complex than many people think (Oakley, 2005). Spelling denotes the ability of a learner to write a word correctly, which involves the process of identifying the spoken word and selecting the appropriate grapheme-to-phoneme correspondence. Spelling is learned as a component of writing, and it is not a result of studying isolated skills. More importantly, effective writing depends on effective spelling; meanwhile, understanding the spelling difficulties of learners can help teachers support the improvement of learner writing. More specifically, the ability to accurately write the spelling of a word largely depends on the necessary skills of written expression. Spelling skill is similar to other skills, including identifying letters and their sounds as well as the word structure.

Given the positive effects of ICT on English language skills, this study intends to manifest this relationship by adopting two programs and investigating their effects on spelling. Spelling programs can develop the writing skill of students and motivate them to write. They can likewise aid students in generating writing in terms of both quantity and quality. Using spelling programs in writing classes facilitates the environment of a student-centered classroom because students are given time to identify and rectify their mistakes while writing the topics. Moreover, spelling programs provide students with the opportunity to control the text and possibilities of editing the text. Spelling programs allow students to edit, save, and return to the text any time. Such programs similarly motivate students to attend writing classes and reduce their anxiety about making spelling errors (Bolter, 2001).

The current study contends that the appropriate use of modality as a principle of computer-based learning could actively foster the learning of spelling. This study helps students enhance and develop their spelling, thereby allowing them to revise their essays and improve their writing. Teaching spelling in conjunction with the pronunciation of words would be appropriate as well. Meanwhile, Jordanian students have difficulty in writing their topics because they have a low level of writing skill, especially in spelling (Rababah, 2003). Obtaining student participation in writing activities in class is an exhausting undertaking. At the same time, writing is a task that is more teacher-oriented than student-oriented. Thus, a new means of facilitating learning should be identified (Bakar, 2009).

\section{PROBLEM STATEMENT}

English is taught in Jordan as a foreign language (EFL) in which students are expected to master the four language skills of listening, reading, speaking, and writing (El-Koumy, 2004). However, most EFL Jordanian students face difficulties in creating a piece of writing (Abuseileek, 2006). One of the major problems is how to correctly spell English words (Rababah, 2003). Several EFL students misspell words, which result in incoherent sentences.

In connection with this idea, Abdel-Jawad (1986) stated that the major writing problems EFL teachers in Jordan face are those associated with student inability to correctly spell English words when attempting to produce a piece of writing. Similarly, Abed Al-Haq (1997) indicated that EFL learners in Jordan are incompetent in writing because they encounter difficulty at the sentence level. Although these EFL students are aware of the importance of spelling in writing, they continue to experience difficulty in correctly spelling English words.

EFL teachers at the higher education level in Jordan are highly interested in improving the writing performance of their EFL students and in enabling them to produce a meaningful piece of writing (Abuhamdia, 1995). To achieve the objectives of teaching EFL in Jordan, teachers direct all their support toward facilitating students with the necessary linguistic skills and enhancing the teaching method required for advanced writing performance (Khuwaileh \& Al-Shoumali, 2000). 
Teachers assert that students generally have problems in writing, especially in spelling, at the tertiary level. The spelling problem begins with university students from the first year until they graduate.

Brown (2000) argued that learners experience challenges in acquiring a foreign or a second language. Similarly, Arab learners encounter numerous difficulties, causing them to make linguistic, semantic, syntactic, and phonological errors. Hilderth (1962) regarded these errors as an indicator of the learning progress and explained that spelling affects student writing: "Spelling is a sort of draft horse of written expression [without which] the load of work in writing cannot be done easily" (p. 2). Hilderth further stated that spelling facilitates student expression of ideas in the writing task. Moreover, Smedley (1983) regarded spelling as an important factor in writing tasks because it strengthens the connection between the writer and the reader.

In Jordan, spelling is ignored at the university level although it has an important position in writing tasks. To the researcher's best knowledge, most Jordanian students have a spelling problem in their writing. Bahlol (2007) reported that spelling is a problem for all learners, even if they are native speakers. Fender (2008) pointed out that most learners have spelling problems. The current study cited the differences that exist between English and Arabic languages as a source of such a spelling problem because these languages are linguistically distant.

Swan and Smith (2001) contended that "all aspects of writing in English cause major problems for Arab speaker(s)" ( $p$. 199). These problems arise due to several factors. For instance, the Arabic writing system is characterized by a right-toleft direction, whereas English adopts a left-to-right writing system. Moreover, Arabic interferences are a contributing factor; for instance, Arabic does not have the voiceless bilabial stop /p/ of English, thus inducing confusion for students who tend to pronounce $/ \mathrm{p} /$ as $/ \mathrm{b} /$. The correspondence between the written form and the spoken form in Arabic is considerably more regular than in English. For instance, the letter /a/ in the words "fan" and "fade" has two different pronunciations. Moreover, English has several silent letters, but Arabic silent letters are very rare.

In Jordan, studies that investigate spelling problems and how they are handled and can be reduced are lacking. This study attempts to fill this gap by investigating spelling errors, suggesting solutions, and establishing a connection between technology and English spelling. Brown (2000) contended that the analysis of student errors predicts and addresses the problems of students. According to Burt (1975), understanding these errors facilitates communication, stating that "relevant teaching [develops] more confident learners and [induces a] more effective communication" (p. 63). Similarly, Burt (1975) investigated the effects of errors on the comprehension of listeners because these errors affect writing and reading. This finding implies a connection between writing and spelling and other aspects of language. Readers often fail to read the message of a writer if it has many errors; consequently, these errors hinder comprehension. Dameraa (1964) revealed that $80 \%$ of misspelled words are the result of a single insertion, deletion, substitution, or transposition of letters.

According to Smedly (1983), "poor spelling and pronunciation interfere to a greater or a lesser degree with communication between writers and readers" (p. 7). Moreover, spelling is an indicator of a well-developed writing ability, whereas spelling errors hinder communication between the writer and the reader. Hilderth (1962) argued that "knowing what the commonest types of spelling errors will put teachers on the lookout for them" (p. 224). This aspect allows teachers to investigate these errors and helps students overcome such errors.

Bahlol (2007) examined Arab students' spelling errors that are very similar to those made by native speakers. An example of such errors is reversing the order of letters in certain words, such as "frist" (should be "first"). Henderson (1981) cited the one-to-one correspondence between the written word and its pronunciation as another reason for the spelling errors of students. Hilderth (1962) investigated the features that affect the spelling errors of students. First, sounds are given to the same letter or combination of letters, as in "break" versus "cream." A single sound can then be expressed by different letters, as in "made" and "say." Bahlol (2007) pointed out that "Arab learners, and possibly most other learners, including native speakers find it quite challenging to utter the same letter /a/ in eight different ways to spell the high front vowel /i/ in 11 different ways" (p. 43). Moreover, learners need to know more letter combinations of 43 phonemes of English, not only 26 letters of the English alphabet. Finally, many silent letters in English, as in "know" and "foreign," and the spelling of words such as "favourite-favorite," cause spelling errors as well.

Smith (1973) pointed out that learners of English face numerous spelling difficulties; for instance, what letters c, $\mathrm{q}$, and $\mathrm{x}$ can do cannot be done by other consonants. The learner should likewise remember all of the pronunciations for the letters and letter combinations in English. For instance, /th/ is unpredictable because this combination of letters is pronounced as $/ \circlearrowright /$ (e.g., "this" and "other") or $/ \theta /$ (e.g., "thing" and "author"). These regularities of English induce numerous spelling problems. Another cause of spelling errors is the mother tongue of learners, which influences the learning of English spelling. As Corder (1993) emphasized, "those speakers whose mother tongue has more similarities to the target language are likely to find it easier to acquire than other speakers whose mother tongue is more distant linguistically" ( $p$. 21). Interference between the first language (L1) and the second language (L2) becomes another cause of spelling errors, particularly when Arab learners have difficulties in pronouncing and spelling $/ \mathrm{p} /$ and $/ \mathrm{v} /$ because these letters do not exist in Arabic. By contrast, Spanish learners easily learn English because these two languages have the same writing system, whereas Arabic and Japanese have dissimilar writing systems.

Smith (2008) further explained the linguistic differences between English and Arabic, which affect the spelling of students: "All aspects of writing in English cause major problems for Arabic speakers" (p. 199). For example, the Arabic equivalent

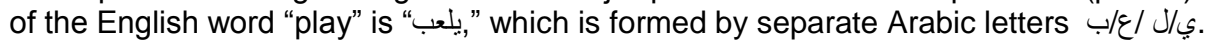


Kharma and Hajjaj (1997) stated that "the greatest difficulty arises from the differences between the seemingly irregular spelling system of English compared with the greater regularity of the predominantly phonetic script of Arabic" (p. 56). The writing system of the Arabic language is principally phonetic. Therefore, Arab learners will look for a sound-symbol correspondence in English words. Moreover, the Arabic language does not double and silent words the way that the English language does, which may cause confusion among Arab learners. The right-to-left mode of the Arabic writing system similarly affects the Arab learners' reading and misspelling of words because the English language has mirrorshaped letters, such as $/ \mathrm{d} /$ and $/ \mathrm{b} /$.

Bahlol (2007) indicated that different from English, the written form in Arabic does not realize vowels, thus affecting the spelling of students. The Arabic language only has consonants and three long vowels, which allows learners to write several words without the use of any written vowel. Hence, Arab learners transfer their knowledge of the Arabic writing system to English, which may cause numerous spelling errors.

Phonological differences between Arabic and English may cause numerous spelling mistakes, which in turn, might affect the pronunciation of students. Odlin (1989) argued that some Arab learners use English words in the same way that they pronounce them. For instance, Alkarki (2005) investigated the problems of Jordanian learners of English. Considering that Arabic does not have a phonemic distinction between $/ \mathrm{p} /$ and $/ \mathrm{b} /$ the way that English does, most Jordanian learners misspell words that have /p/ and /b/ (i.e., writing "blaying" instead of "playing"). Research similarly suggested that spelling errors negatively affect the writing proficiency of students. This finding implies that language background causes the spelling problem of Arab students. In other cases, students pronounce "friend" as "frend" and omit /i/ in the pronunciation, although it exists in the word. In vowels, /iy/ is spelled in many ways, such as "receive" (/risiyv/) and "free" (/friy/). In sum, English spelling is difficult to learn for Arabic speakers of English in Jordan principally because of the pronunciation variations between English and Arabic.

In a preliminary study, the researcher investigated whether or not the students have spelling errors in their writing. Fortythree students were asked to write about "accidents on highways." The researcher analyzed their writing and classified the errors into different types in Table 1

Table 1 Numbers of Learners Making Spelling Errors

\begin{tabular}{|c|c|c|c|}
\hline Type of Error & No. of Learners & Actual Word & Example \\
\hline $\begin{array}{l}\text { Insertion } \\
\text { (add a letter to the } \\
\text { word) }\end{array}$ & $24 \quad 55.8 \%$ & hour & houre \\
\hline $\begin{array}{l}\text { Omission } \\
\text { (omit a letter from the } \\
\text { word) }\end{array}$ & $28 \quad 65.11 \%$ & friend & frind \\
\hline $\begin{array}{l}\text { Substitution } \\
\text { (substitute a letter with } \\
\text { another one) }\end{array}$ & $3274.41 \%$ & few & vew \\
\hline $\begin{array}{l}\text { Transposition } \\
\text { (reverse the order of } \\
\text { two letters or more) }\end{array}$ & $8 \quad 18.60 \%$ & because & becaues \\
\hline No errors & $2.32 \%$ & 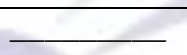 & 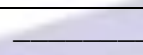 \\
\hline
\end{tabular}

The researcher likewise analyzed the errors according to the frequency of different types of spelling errors (see Figure 1 in the subsequent section). 


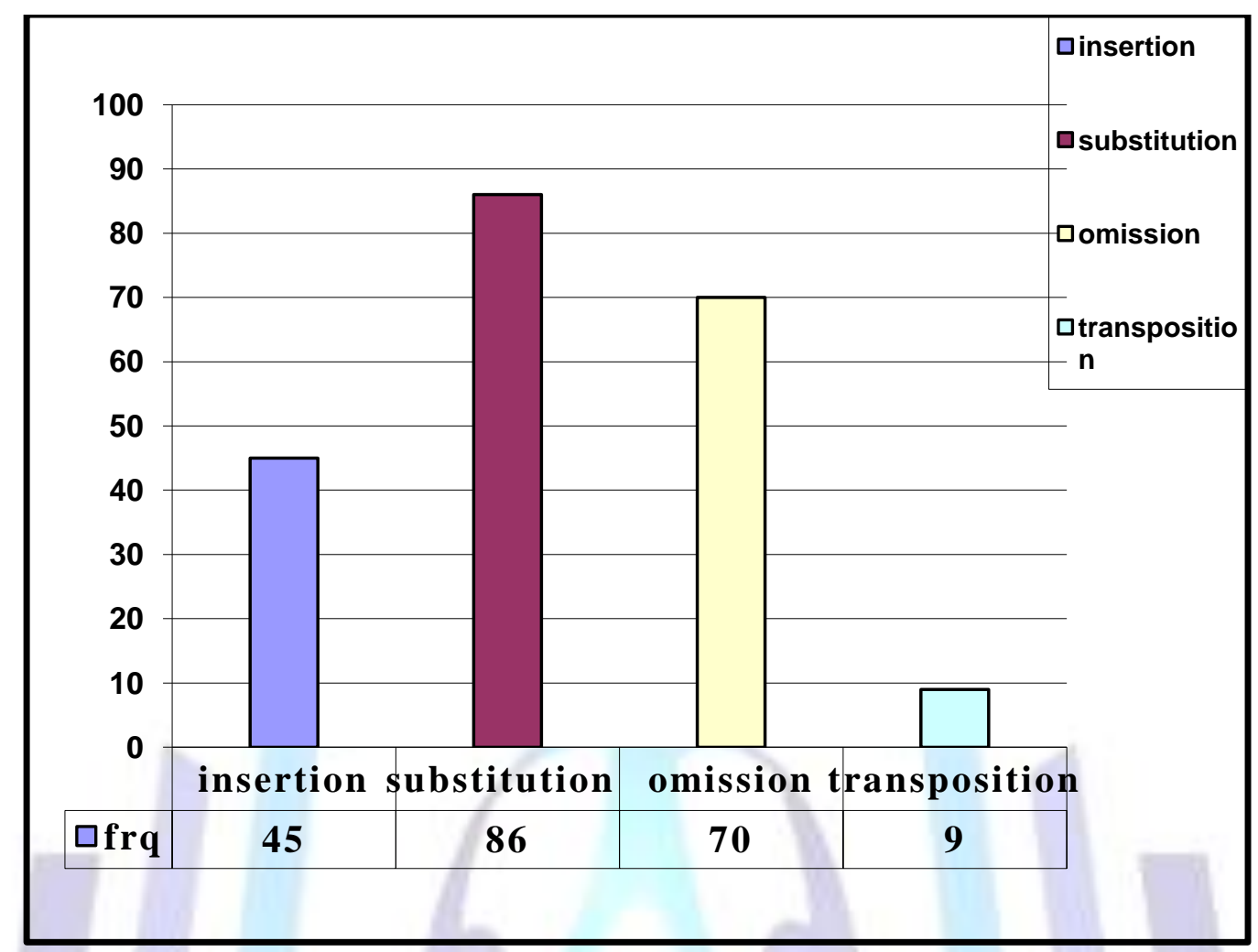

Figure 1 Frequencies of Spelling Errors

The results indicated that the most common spelling mistakes made by the learners were substitution and omission errors; notably, students have difficulty in using actual words in their writing. Moreover, the students used close words that express semi-meaning as well as wrote Arabic words with English letters and actual Arabic words.

Despite the importance of spelling in producing meaningful written texts, the researcher observed that spelling has not been given the attention that it deserves in Jordan. Moreover, teachers do not sufficiently help weak spellers; they require additional training in the area of spelling. The researcher intends that through this study, which investigates the effect of two computerized programs on spelling among English language students at Hashemite University, scholars will focus on the spelling problem that Jordanian EFL students encounter.

With regard to the effect of computer usage on foreign language learning, the majority of previous studies focused on writing skill in general. Abuseileek (2006) explored the effects of the word processor on the writing achievement of students and paid no attention to spelling. Tsou (2008) examined web-based writing programs and their effects on the writing of students in general, without focusing on spelling errors. The current study contends that English spelling can be improved if the modality principle is considered. Therefore, this study explores two computerized programs that deal with the following two aspects:

- $\quad$ Comparing text-audio and text modes to test the modality principle.

- Testing the modality principle with three levels of spelling errors.

This study principally aims to examine the effects of the two computerized programs on improving the learning of spelling among Jordanian university students. Specifically, the study investigates whether any significant differences in reducing spelling errors exist between students taught via the text and audio (TA) mode and those who are taught via the text (T) mode.

In this regard, this study explores the effects of the two programs on spelling errors made by English language students at Hashemite University in Jordan and provides recommendations and suggestions to enable both university teachers and students in Jordan to improve their written work quality as well as reduce the spelling errors of students.

\section{Research Questions:}

1. What are the effects of the text-audio mode and text mode on the four types of spelling errors (i.e., transposition, insertion, omission, and substitution)?

2. Does the audio effect of the text-audio mode affect students with high, medium, and low levels of spelling errors?

\section{THEORETICAL FRAMEWORK}


The theories and approaches underlying this study are cognitive theory of multimedia learning, spelling in the context approach, and dual route theory of efficient spelling. The details of these theories are described below.

\section{A. Cognitive theory of multimedia learning (CTML)}

Computers have the capacity to control different variables and analyze data in various forms and in different fields, such as mathematics and science. Students can use computers to facilitate their understanding of concepts that they use in their study and correct their misconceptions (Ricci \& Bea, 2002). Multimedia use involves three major elements, namely, delivery of media that uses certain tools for presenting the learning material, including using books and computers; presentation mode, which refers to the system of presenting the learning material, such as word system or images system; and modalities mode, which denotes the method that the learner uses in processing information either visually or auditorily (Mayer, 2003).

\section{Dual-channel assumption}

This assumption focuses on the separation of the information processing channels by humans for auditorily and visually presented material. In the dual coding model in learning from multimedia, the sound and text are processed in different channels in the working memory; the links are subsequently built between them (see Figure 2).

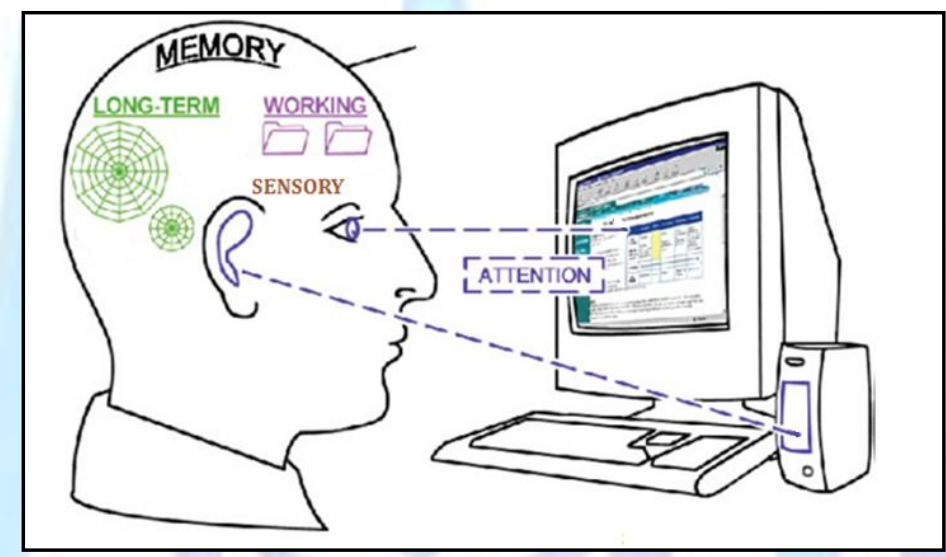

Figure 2 dual coding theory of learning from multimedia

(Clark \& paivio, 1991)

The researcher focuses on the modality principle, which suits the study and the adopted computerized programs.

\section{Modality principle}

The modality principle focuses on combining visual and verbal channels to explain the material, thus increasing the working memory and facilitating learning (Moreno, 2006). Moreno and Mayer (2001) asserted that adding visual materials to audio over the text alone increases the learning outcome and ultimately benefits the students. Moreover, this process facilitates student learning of the spoken text more than the printed one.

\section{Audio-effect in modality}

Most students had difficulty in specifying an accurate presentation of sounds and words. This difficulty appeared in their spelling errors; moreover, it signified their weak phonological awareness of English sounds. Focusing on the phonological awareness of each sound became inevitable. Students were required to learn the pronunciation or sounds in English to be able to discriminate these sounds in terms of spelling and reading. For instance, Arab students have a problem with voiced and voiceless sounds, such as /p/ and /b/, /t/ and /d/, as well as with fricatives /f/ and /v/, /th/ as in "thing" and /th/ as in "that." Moreover, the Arabic language has only three vowels, whereas English has short, long, and diphthong vowels. Therefore, students cannot differentiate between these vowels in English; for instance, a long vowel in "plad" for "played" shows the omission of vowels and an inaccurate vowel transcription, such as /i/ in "hit." In English, spelling does not represent each sound in the word and may not include all of the consonants and vowels in the word. English spelling is evidently complex; thus, students must use techniques, programs, and skills to develop their spelling of English word

\section{B. Spelling in the context approach}

Writing and spelling are interrelated components of language. Writing, which is the process of composing and expressing ideas, should be taught as an integral part of literacy. Swander, Leahy, and Cantrell (2007) argued that spelling cannot be taught in isolation; it must be integrated with the teaching of reading and writing. Moreover, the relationship between sound and written symbol is essential, and spelling is the key to writing and reading .

\section{DUAL ROUTE THEORY OF EFFICIENT SPELLING}


Dual route theory is based on two independent routes that are essential for storing and retrieving information in spelling (Coltheart, 1978). The orthographic route encompasses direct access and storage of lexical units in a mental dictionary. By contrast, the phonological route encompasses establishing and recalling the correspondence of sounds, letter clusters, and syllables with graphemes.

\section{METHODOLOGY}

The sample comprised 80 students who were enrolled in writing courses. This sample was assigned by the registration department of Hashemite University. The registration department also formed two writing sections according to the registration lists. Two English language professors who were holding Ph.D. degrees in the English language participated in this study. These professors had more than three years of teaching experience in Jordanian universities. These professors were trained in using Microsoft Word 2007 and Ginger.

First treatment: The professor taught the students how to write topics using Ginger. The students were also taught how to handle and write topics using this program. The students wrote their compositions in each lecture using this program.

Second treatment: The professor taught the students how to write topics using Microsoft Word 2007. The two treatment groups studied the same material that was given by the two professors. However, the first group used Ginger, whereas the second group used Microsoft Word 2007.

\section{Study Instruments}

The following instruments are used in this study:

1. Writing achievement tests (pre- and post-test)

2. Instructional software (Ginger and Microsoft Word 2007)

3. Structured interview questions

4. Cook's classification

\section{RESULTS}

Results for the first question

Figure 3 shows that the transposition errors of the students in the text-audio group have decreased.

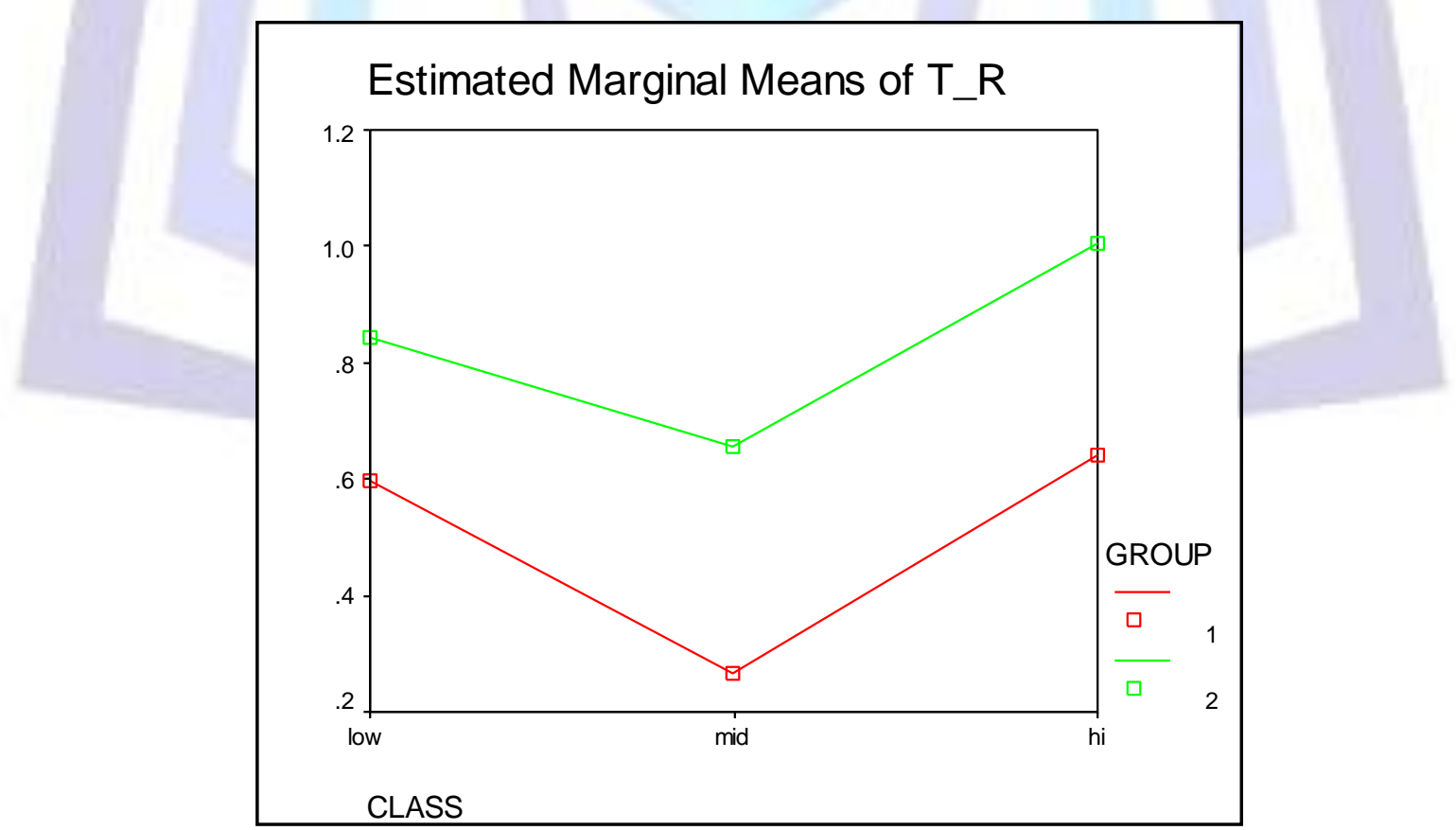

Figure 3. Mean Post-Test Scores of the Two Groups on Transposition Errors

Figure 4 shows that the omission errors of the students in the text-audio group have decreased. 


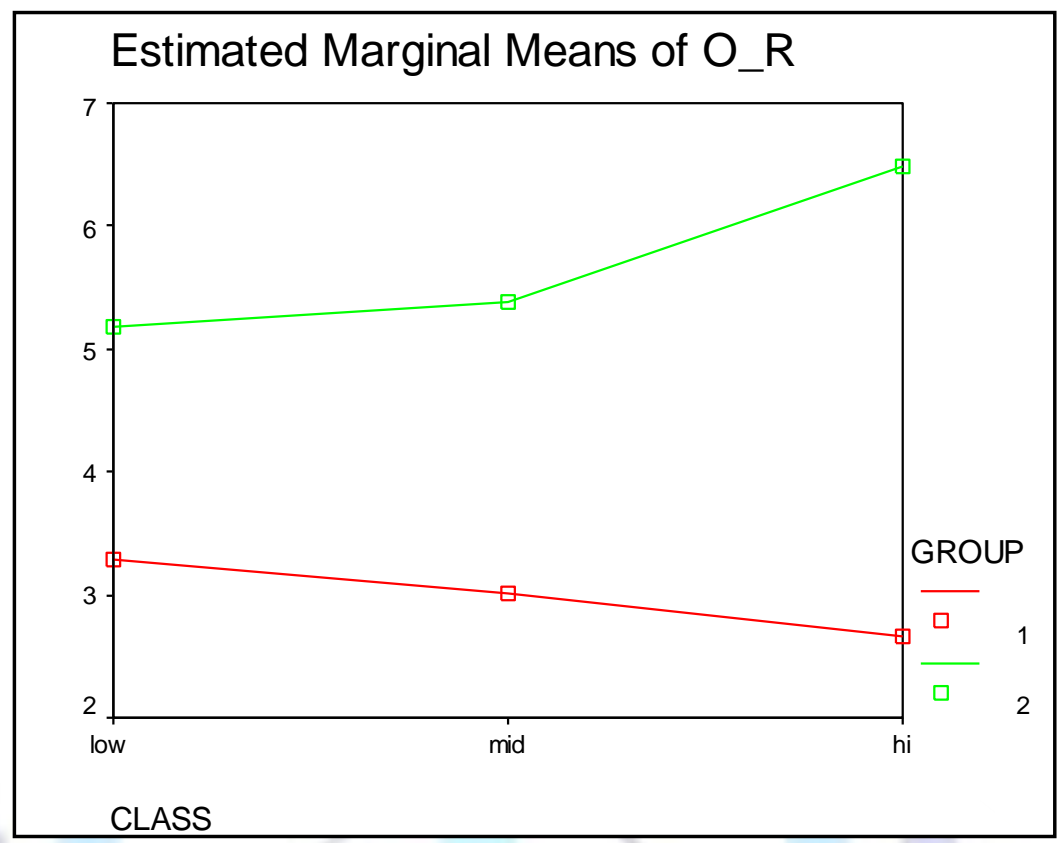

Figure 4. Mean Post-Test Scores of the Two Groups on Omission Errors

Figure 5 shows that the insertion errors of the text-audio group have decreased.

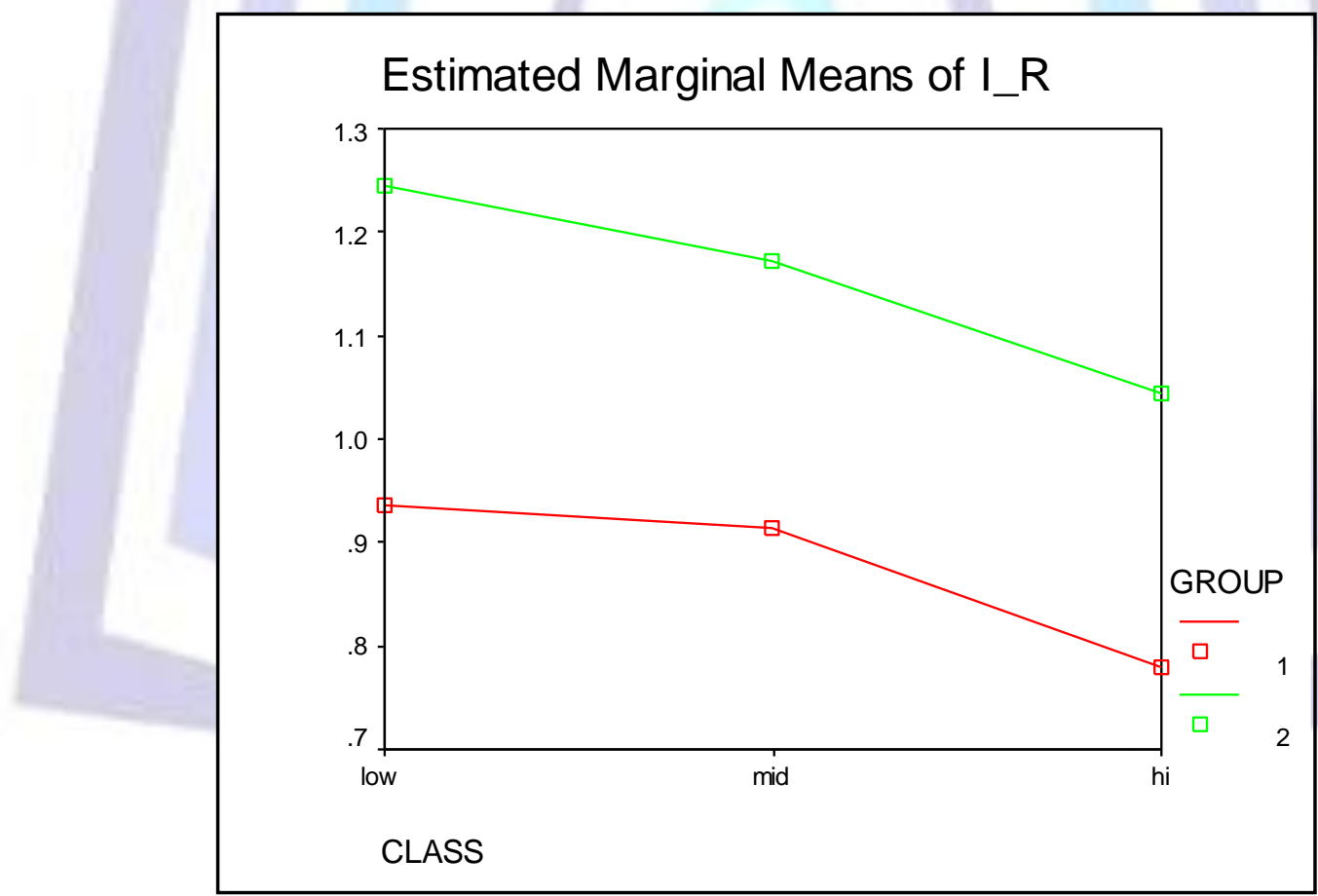

Figure 5 shows that the Insertion errors of the text-audio group have decreased.

Figure 6 shows Mean Post-Test Scores of the Two Groups on Substitution Errors 


\section{Estimated Marginal Means of S_R}

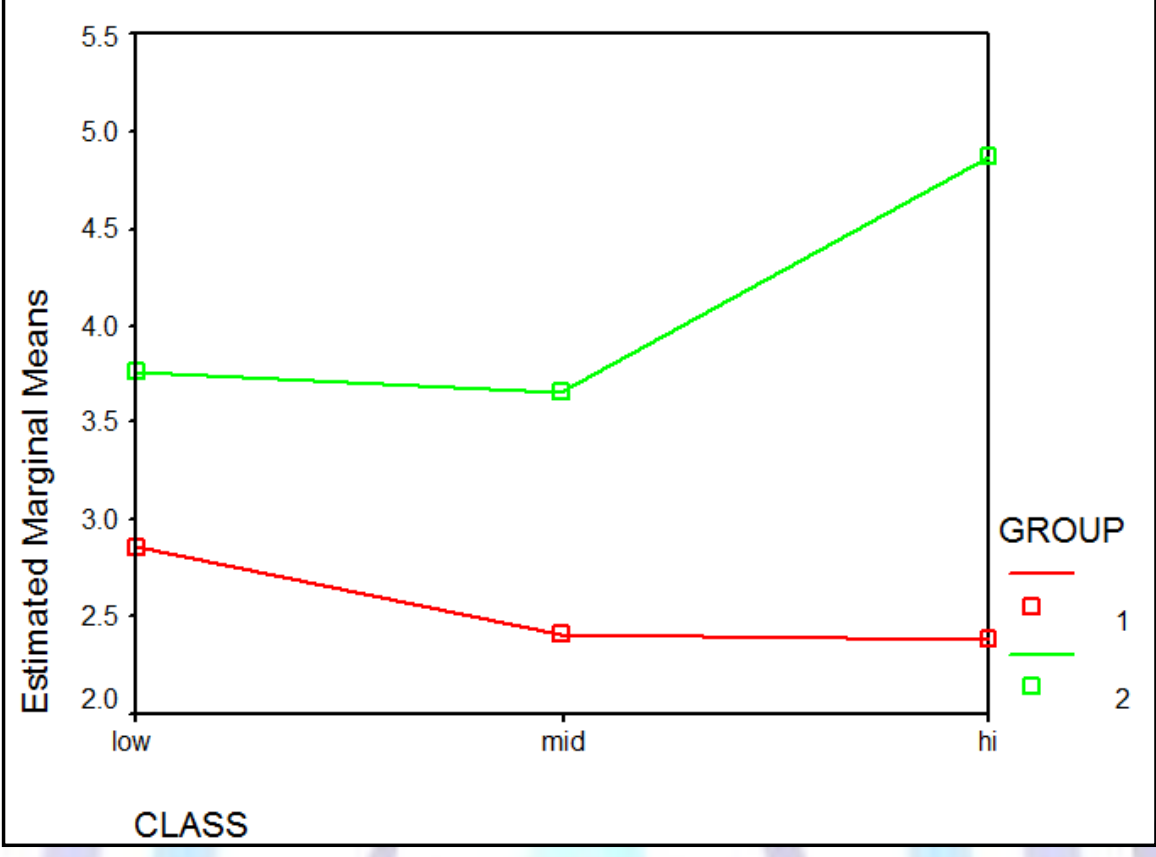

Figure 6. Mean Post-Test Scores of the Two Groups on Substitution Errors

\section{Results for the second Question}

Does the audio effect of the text-audio mode affect the students with high, medium, and low levels of spelling errors?", is answered by asking structured interview questions.

The following structured interview questions were likewise asked to investigate the effects of adding audio effect to the text mode:

1. In what manner did the audio effect simplify the spelling of words for you?

2. Was listening to the words on Ginger a very interesting activity? Why or why not?

3. Was your spelling performance improved by your use of Ginger?

The following underlying themes were identified from the interview comments using an inductive approach in which themes and patterns emerged from the data:

1. Learners require multiple input modalities.

2. Audio effect reinforces and confirms what is taken in spelling.

3. Audio effect improves the pronunciation of learners.

These themes relate to the fourth research question.

A few examples of learner responses to these three questions are presented below.

The participants were interviewed after the implementation of the study to further investigate the effects of adding the audio effect with a computer program. The post-interview results indicate the following points:

The students answered the first question as follows: Student 1: "When I listen to the word, I become able to recognize such word and its letters easily." Student 2: "I learn about the pronunciation of the word." Student 3: "Listening to the word on Ginger help me to know more words." Student 4: "I can understand how to write a word." Student 5: "Listening to the words and their pronunciation develop my listening skills." Student 6: "I focus on the pronunciation of the word to ease my difficulties in learning spelling."

The students answered the second question as follows: Student 1: "I can use the audio effect for more than once to understand the exact spelling of the word." Student 2: "Listening directly to the words lets me enjoy and improve my learning." Student 3: "The audio effect is interesting to use as I can listen to all the words simultaneously." Student 4: "Using the audio effect is interesting; I can replay the audio and listen many times to the spelling of words." Student 5 : "I can listen to the words that I might miss." Students 6: "I like listening to the words; I can pause at a certain point when I cannot clearly understand the spelling of a word." 
The students answered the third question as follows: Student 1: "I discovered that listening to the word on Ginger is more enjoyable than reading the word because using this program improves my spelling of words." Student 2: "I enjoy using technology in learning; Ginger made the spelling material more flexible." Student 3: "I can spell words correctly." Student 4: "Using Ginger is very enjoyable as this program makes studying more accessible and easier." Student 5: "I can use Ginger anytime and anywhere. I also recommended this program to my friends in other colleges to help them with their spelling." Student 6: "I feel comfortable using Ginger in class, and I feel happy that I can understand the spelling of words using this program."

\section{DISCUSSION}

One of the major difficulties for this study was the lack of related research on the role of technology in improving the spelling of students

\section{Discussion for the First Question}

The first question, "What are the effects of the text-audio and text modes on the spelling errors of the students?", was related to the differences between the two groups that used Microsoft Word 2007 and Ginger in terms of their spelling errors. These two modes were compared with each other. A clear difference was found in the capability of these modes to reduce the spelling errors of the students in the two groups. For example, the mean post-test score of the text-audio group (6.889) was lower than that of the text group (11.733), which indicated that the errors of the students in the audiotext group decreased. The students in the text-audio group likewise obtained lower spelling errors compared to the students in the text group. Statistically significant differences were also found between these groups in terms of the dependent variable. The effects of using the two modes of presentation on reducing the substitution, omission, insertion, and transposition errors of the students were investigated. For example, the students in the text-audio group obtained less transposition errors compared to those in the text group. The former obtained a mean of 0.3250 and a standard deviation of 0.57233 , whereas the latter obtained a mean of 1.1000 and a standard deviation of 1.46410 .

The spelling errors of the students who used the text-audio mode largely decreased compared to those of students who used the text mode because the former helped the students in letter recognition, basic vocabulary, writing, and spelling. For example, the students listened to the pronunciation of words in the text-audio mode, hence helping them spell such words. Moreover, students can listen to their selected words and sentences for more than once using the text-audio mode. This feature helped the students maintain visual contact with the voiced text.

These results can be attributed to several factors. Mayer (2001) stated that learners could process a limited amount of information occurring in each channel at a single time. Consequently, the information that can be processed through the two channels is balanced. The word enters through the eyes and is processed in the visual/pictorial channel, whereas the spoken word enters through the ears and is processed in the auditory/verbal channel. Therefore, none of these channels is cognitively overloaded. This study clarifies such finding by revealing that learners can process the words that they have written through their eyes, and that they can process the words that they have listened to through their ears. Therefore, these students were able to process words in both their visual and auditory systems.

this study emphasizes the importance of spelling to vocabulary development and its relationship with pronunciation. The students in the text-audio group claimed that they saw, heard, and recognized how words were written, which affected their spelling development. The text-audio mode also strengthened the spelling memory, vocabulary, and pronunciation skills of these students. Learning how to spell in context helped the students develop their spelling and provided them with an excellent vocabulary repertoire. Spelling is the key for many skills, including vocabulary, writing letter/sound correspondence, and reading. The results of this study were in accordance with the results of many other studies that confirmed the effectiveness of the modality principle in learning. For example, Sabet and Shalmani (2010) emphasized the use of audio facilities in instructional programs, whereas Aldalalah and Fong (2008) indicated that the effectiveness of the working memory in learning music in Jordan depends on the modality principle. However, Moreno (2006), Moreno and Mayer (2001), and Aldalalah, Fong, and Al-Ababneh (2010) reported that combining sounds with animation could reduce visual channel overload.

\section{Discussion For The Second Question}

It focused on the audio effect in the text-audio mode (i.e., Ginger). Studying contextual spelling, which focused on studying spelling within the context and not in isolated words, helped the students reduce their spelling errors in texts. The four types of spelling errors were significantly reduced when the students learned how to spell in context rather than in isolated words. This approach also helped them memorize the words, but they forget these words after a short time. Similar to this approach, the text-audio mode in Ginger reduced the four types of spelling errors that were committed by the students. Therefore, a strong relationship was established between the contextual spelling approach and the modality principle.

A connection was similarly established between the reading and the spelling of a word. For instance, despite seeing the word "hospital" after visiting the hospital for many times, the students were unable to remember how this word was spelled as could be seen in their misspelled words "hosbital" and "hosptal." In other words, the students were able to read the word but were unable to recall the sequence of letters when they attempt to write the same word. Reading represents the ability to recognize and pronounce a single word, whereas spelling focuses on the ability to write the correct sequence of letters in a word. The participating students tended to apply the sound-letter correspondence rules, which was an 
unsatisfactory strategy. These errors were likewise attributed to the failure of these students to relate a phoneme with the grapheme. For example, the students were unfamiliar with the exact spelling rule for the final $e$ as shown in their misspelling of "gat" instead of "gate." The students did not pronounce the word without the final $e$ as the vowel was pronounced short. This finding is consistent with that of Wagner and Barker (1994), who examined the connection between orthographic and phonological knowledge (i.e., remembering to code a long vowel sound in a word using the final e) as well as the effects of phonological and orthographic knowledge on spelling performance.

Ehri (2000) examined the effects of remembering the spelling of the word during its pronunciation as well as the repetition bonds among the spelling, pronunciation, and meaning of a word. Some spelling errors were also derived from the speech sound. For example, by spelling "amount" as "amont," the students omitted the nasal consonant before a stop consonant. This case demonstrated that the students applied rote learning, which concerned the memorization and mastery of the spelling of words. However, this strategy is imperfect for mastering spelling. The spelling problems of the students were attributed to their ignorance of the orthographic systems in the English language. A script can be recognized either by eye, in which the text goes from print to meaning, or by ear, in which the text goes from print to sound, and then from sound to meaning. When the students processed the letters by eye, they mastered the recognition and meaning of words. By contrast, when these letters were processed by ear, the students mastered the words, their meaning, and the graphemeto-phoneme correspondences. When recognizing the words by ear, the students must entirely focus on the correct sequence of all of the letters in a word, whereas when recognizing the words by eye, the students must follow the partial cues of words, which depend on the letter cancellation task. These recognition processes also provide a poor basis for the letter-by-letter program that is necessary for accurate spelling. This argument concurs with the findings of Leong (1998), who found connections between the phonological and orthographic sections for effective spelling. He likewise argued that some phonologically regular words could be spelled by matching each sound to a letter, but other words could not be spelled in the same manner. Auditory modality suits the letter-by-letter strategy and the recognition of the correct sequence of letters, whereas visual modality suits the spatial representation of letters.

\section{Recommendations for Researchers}

1. Researchers must design and develop more spelling courseware that integrates the modality principle according to Mayer's cognitive theory.

2. Researchers must investigate the applicability of the modality principle with other grades or stages.

3. Researchers must integrate the modality principle in the design and development of other fields in writing, such as contextual spelling.

\section{REFERENCES}

1. Abdel-Jawad, H. (1986). A linguistic analysis of spelling errors made by Jordanian university students, Abhath AlYarmouk, Yarmouk University, 4.1:19-31.

2. Abed Al-Haq, F. (1997). Production of English sentence stress by Yarmouk university majors. Journal of the College of Teachers, Al-Mustansiriah University (Iraq), 9: 1-21.

3. Abuhamdia, Z. A. (1995). Coordination in ESL writing: Is its use culture-specific?Multilingual: Journal of cross-cultural and interlanguage communication, 14.1:2

4. AbuSeileek, A. F. (2006). The Use of word processor for teaching writing to EFL learners in

5. King Saud University. Journal of King Saud University.

6. Albirini, A. (2004). An exploration of the factors associated with the attitudes of high School EFL teachers in Syria toward information and communication technology. Ph.D.thesis. The Ohio State University.

7. Aldalalah, O. \& Fong, S. F. (2008). Effects of modality principles among Jordanian students. $2^{\text {nd }}$

8. International Malaysian Educational Technology Convention, 5-7 November 2008, Kuantan,

9. Malaysia. Malaysia: Malaysian Educational Technology Association.

10. Aldalalah, O., Fong, S. \& Ababneh, Z. (2010). Effects of modality principle on The Learning of

11. Arabic language among first grade pupils in Jordan. Jordan Journal Of Educational Sciences.

12. Al-Karaki, E. (2005). An analysis of spelling errors made by school students in AlKarak

13. Directorate of Education. Unpublished thesis, Mu"tah University, Al-Karak.

14. Bahloul, M. (2007). Spelling errors of Arab learners: Evidence of intergraphic mapping. In C. Coombe \& L. Barlow (Eds). Language Teacher Research in The Middle East, (pp. 41-51). Mattoon, III: United Graphics, Inc.

15. Bakar, N. A. (2009). E-Learning environment: blogging as a platform for language learning.

16. European Journal of Social Sciences, 9(4), 584-604.

17. Barkaoui, K. (2007). Rating scale impact on EFL essay marking: A mixed-method study.

18. Assessing Writing, 12(2), 86-107.

19. Bolter, J. D. (2001). Writing space: computers, hypertext, and the remediation ofmprint.

20. Brown, H. D. (2000). Principles of language learning and teaching (4 th. ed.). White Plains, NY: Pearson Education.

21. Burt, K. M. (1975). Error Analysis in the Adult EFL Classroom. TESOL Quarterly, 9(1), pp. 53-63. Retrieved August 31, 2010, from JSTOR database. 
22. Chen, C., \& Cheng, W. Y. (2006). The use of a computer-based writing program: facilitation or frustration? Online Submission, 15.

23. Clark, J. M., \& Paivio, A. (1991). Dual coding theory and education. Educational Psychology

24. Review, 3(3), 149-210.

25. Coltheart, M. (1978). Lexical access in simple reading tasks. In G. Underwood (Ed.), Strategies of information processing (pp. 151-216). New York: Academic Press.

26. Corder, P. (1993). A role for the mother tongue. In Gass, M. S. \& Selinker, L. (Eds.), Language transfer in language learning, (pp. 18-31). Philadelphia: John Benjamin Publishing Company.

27. Ehri, L. (2000). Learning to read and learning to spell: Two sides of a coin. Topics on Language Disorders, 20(3), 19-36.

28. El-Koumy, A. (2004). Teaching and learning English as a foreign language: a Comprehensive

29. approach. online submission, 175.

30. Elliot, S., \& Mikulua, C. (2004). The impact of MY Access! use on student writing performance: A technology overview and four studies. Paper presented at the Annual Meeting of the American Educational Research Association, San Diego, C.A.

31. Hildreth, G. (1962). Teaching spelling: a guide to basic principles and practices. New York:

32. Holt, Rinehart and Winston, inc.

33. Kapka, D., \& Oberman, D. (2001). Improving student writing skills through the modeling of the

34. writing process

35. Kharma, N. and Hajjaj, A. (1997). Errors in English among Arabic speakers: Analysis and

36. remedy. Beirut, Lebanon: Librairie du Liban Publishers.

37. Khuwaileh, A. A., \& Shoumali, A. A. (2000). Writing errors: A study of the writing ability of Arab learners of academic English and Arabic at university. Language, Culture and Curriculum, 13(2), 174-183.

38. Leong, C. K. (1998). Strategies used by 9-to-12-year-old children in written spelling. In C.

39. Mayer, R. E. (2001). Multimedia learning. New York: Cambridge University Press.

40. Mayer, R. E. (2003). Multimedia learning. Cambridge University Press.

41. Moreno, R. \& Mayer, R. E. (2000). A coherence effect in multimedia learning: The Case For

42. minimizing irrelevant sounds in the design of multimedia instructional messages. Journal of

43. Educational Psychology, 92(1), 117-125.

44. Moreno, R. (2006). Does the modality principle hold for different media? A test of the Method

45. affects learning hypothesis. Journal of Computer Assisted Learning, 22(3), 149-158.

46. Odlin, T. (1989). Language transfer: Cross-linguistic influence in language learning.Cambridge: Cambridge University Press.

47. Park, C., \& Son, J. (2009). Implementing computer-assisted language learning in the EFL classroom: teachers' perceptions and perspectives. International Journal of Pedagogies and Learning, 5(2), 80-101.

48. Rababah, G. (2003). Communication problems facing Arab learners of English: A personal perspective. TEFL web journal, 2(1), 15-30.

49. Ricci, C. M. \& Bea, C. R. (2002). The effect of interactive media on children's story memory.

50. Journal of Educational Psychology, 94(1) 138-144.

51. Sabet, M. K. and H. B. Shalmani (2010). Visual and spoken texts in MCALLCourseware: the

52. effects of text modalities on the vocabulary retention of EFL learners. English language teaching

53. 3(2): P30.

54. Smedley, D. (1983) Teaching the basic skills: Spelling, punctuation and grammar in secondary English. London: Methuen.

55. Swan, M., \& Smith, B. (2001). Learner English: A teacher's guide to interference

56. And Other problems: Ernst Klett Sprachen.

57. Smith, F. (1973). Decoding: The great fallacy. In F. Smith (Ed.), Psycholinguistics and Reading

58. (pp. 70- 89). New York: Holt, Rinehart and Winston, inc.

59. Smith, B. (2008). Arabic speakers. In M. Swan \& B. Smith (Eds.), Learner English: Ateacher's

60. guide to interference and other problems (2nd ed.). Cambridge: Cambridge University Press.

61. Swander, M., Leahy, A., \& Cantrell, M. (2007). Theories of creativity and creative writing

62. pedagogy. The Handbook of Creative Writing, 11.

63. Tsou, W. (2008). The Effect of a Web-Based Writing Program in College English Writing

64. Classes. 